\title{
EL ACTO DE NARRAR: RELACIONES ENTRE AUTOR Y NARRADOR
}

\author{
SAnTIAGo Trancón \\ IES Calderón de la Barca (Madrid) \\ e-mail: strancon@gmail.com
}

\section{RESUMEN}

A partir del análisis de la estructura narrativa de Memorias de un judío sefardí se realiza una reflexión teórica sobre las relaciones entre autor y narrador, vida y literatura, sujeto y lenguaje. Tomando como referente el Quijote, y aplicando la teoría psicoanalítica, se estudia la función básica del sujeto de la enunciación en la construcción de la diversidad de voces narrativas en las que el yo del autor se borra o disuelve.

PALABRAS ClAVE: Autor, narrador, sujeto de la enunciación, lenguaje, voz narrativa, novela.

\section{AbSTRACT}

From the analysis of the narrative structure of Memorias de un judio sefardí, there is a theoretical reflection on the relationship between author and narrator, between life and literature, subject and language. Taking the Quijote as a reference, and applying the psychoanalytic theory, we study the basic function of the speaking subject in the construction of the different narrative voices, in which the author's self is deleted or dissolves.

KEY WORDS: Author, narrator, speaking subject, language, narrative voice, novel. 
Recientemente he publicado Memorias de un judio sefardí. La verdadera historia de Dan Kofler ${ }^{1}$. Me propongo reflexionar aquí sobre sus claves literarias y narrativas. Se trata de un ejercicio de autocrítica o autoanálisis cuyo sentido y finalidad debo aclarar. Parto del supuesto teórico de que toda obra literaria contiene elementos y referencias cuya interpretación nos lleva al autor, pero que, una vez publicada, la obra no mantiene ningún vínculo especial con el autor, pues se desliga de él para convertirse en una entidad autónoma y autosuficiente. Partiendo de esta premisa, y como lo haría un lector crítico, voy a realizar un análisis de estas Memorias desde el punto de vista del acto narrativo, lo que implica aclarar las relaciones que se establecen entre autor y narrador dentro de la obra misma, tal y como el texto las construye y manifiesta.

Toda obra publicada encierra para el autor (pero también para el lector) un engaño, una ilusión de pertenencia que nace del hecho de que en la portada del libro figure su nombre como autor del texto, del que se responsabiliza social y legalmente. Pero desde el momento mismo en que un autor asume la autoría de una obra, incluso desde el instante en que inicia su escritura, se le plantea una contradicción y una lucha que es precisamente la primera que ha de encarar y que no le abandonará a lo largo de todo su trabajo: decidir quién escribe. Me refiero, no a la evidencia de que él es el que va a realizar el acto de escribir, sino quién va a ser el sujeto de la enunciación del texto que escribe. Naturalmente, decidir quién va a ser el sujeto del texto, la voz a la que el lector va a atribuir los enunciados (con independencia de que sean versos, reflexiones, historias o ficciones) supone condicionar el texto mismo, no sólo lo que se puede escribir o contar, sino el tono, el punto de vista y la distancia entre él y lo escrito y, en general, el efecto de realidad, de verdad y de verosimilitud que el texto va a ir construyendo y transmitiendo al lector. Digo que se le plantea una contradicción y una lucha, porque el autor debe definir las relaciones que él mismo, como autor real o persona física y psicológica, va a mantener con el sujeto del texto, en qué medida va a tratar de imponerse o proyectarse sobre él o, por el contrario, dotarle de suficiente libertad como para acabar siendo sustituido por ese otro, el sujeto del texto, el único con el que el lector va a establecer una relación. O sea, que ha de aceptar que él, como persona real, ha de borrarse o diluirse en la voz de otro. Este hecho es especialmente importante en el caso de la narración. Por muchos esfuerzos que haga el autor por confundir su voz con la del narrador, nunca será él el verdadero sujeto de la enunciación del texto, sino ese otro que se interpone entre él y el lector, y que lo sustituye.

Inicio esta reflexión sumergido en la perplejidad que siempre me ha producido la lectura de mis propias obras. No puedo evitar el sentir la misma distancia que cualquier lector pueda experimentar ante esos mismos textos. Puede que sea un caso extremo, cuya explicación debiera buscarse en la psicología, pero, incluso aceptando esta posibilidad, el problema que aquí planteo creo que es esencial y tiene que ver con el acto mismo de narrar, pues no hay posibilidad de construir una narración sin narrador, y el narrador es necesariamente una voz que exige diferenciarse del autor para poder existir. Porque, ¿quién habla cuando yo escribo?

La pregunta presupone una escisión entre autor y narrador -y entre autor y obra-, lo que nos obliga a indagar, no sólo sobre al acto de narrar y escribir, sino sobre la relación

\footnotetext{
1 Madrid: Infova Ediciones, 2011.
} 
última entre la palabra y el yo. La duda, la perplejidad nace del hecho de que la palabra escrita se vuelve exterior y permanente, mientras el yo del autor-origen empírico de la escritura- se diluye en una entidad imaginaria.

La relación entre el autor y su obra es, por tanto, semejante a la que existe entre el yo y el lenguaje. Al desprenderse del autor, el texto revela su verdadera naturaleza, que es, no la de ser el producto efímero de un yo, sino la de dar consistencia y continuidad imaginaria a ese yo. La escritura, al objetivar el texto y la palabra, produce la ilusión de dar consistencia a un yo real, el del autor, pero en realidad sólo da consistencia a un yo imaginario, el del narrador. Lo que la escritura en definitiva pone en evidencia es la ilusión de autoría, en el sentido de que la obra provoca una identificación ilusoria entre autor y narrador. Pero es precisamente aquí, en este espacio lleno de brumas, donde corre mayor peligro el proceso de escritura, pues en la medida en que el autor quiera estar presente en el texto, apropiárselo y utilizarlo como espejo para reflejar su yo, el acto mismo de la escritura pierde su sentido.

Son estos problemas los que he tratado de encarar en estas Memorias. El género memorialístico o autobiográfico pone especialmente de manifiesto las contradicciones entre sujeto y lenguaje, entre autor y narrador. Nace del equívoco de que el autor y el narrador son la misma persona y, por tanto, se trata de una sola voz. El lector acepta este supuesto y las dudas se dirigen, no hacia la naturaleza de esa entidad narradora, sino hacia la verdad de los hechos narrados y la sinceridad del autor al contarlos. Pero ni siquiera en este caso podemos ignorar la escisión existente entre autor y narrador, aunque se identifiquen lingüísticamente al usar el pronombre yo y la primera persona verbal. El autor tiene que construir la voz del narrador como un sujeto de la enunciación, con el que se identificará, pero no podrá evitar que ese sujeto no sea él mismo, sino una especie de doble o sustituto literario. Su ser empírico real debe dejar paso a ese otro ser literario, construido y sostenido sólo con el lenguaje.

El primer problema que se me planteó, al inicio de la escritura de estas Memorias, fue precisamente el de superar las limitaciones de ese autor-narrador. El género autobiográfico obliga al uso de la primera persona y, por tanto, a construir un yo permanente como sujeto de la enunciación. Para dar coherencia a ese yo, el texto tiene que limitar sus posibilidades enunciativas y narrativas. Pero el planteamiento originario era que yo contara la vida que otro me iba a contar. ¿Cómo hacerlo? ¿Cómo dar coherencia, verdad y verosimilitud a un relato que va a ser transmitido a través de la voz de otro? Me movía entre dos polos: el de la autobiografía y el de la biografía. Podía articular el relato alternando esas dos voces: la primera persona (autobiográfica) y la tercera (biográfica). Pero yo no quería escribir ni una biografía ni una autobiografía, sino una historia «novelada». Formulé el propósito de este modo: «Quiero escribir una historia que pueda leerse con el interés de una novela, donde aparezcan los hechos, la efímera e inquietante realidad de los hechos, sin ficción alguna, pero con la fuerza y la verdad que sólo la literatura y el arte le pueden otorgar a la vida».

El reto era, por tanto, no inventarme una historia, sino transmitirla; no falsear lo hechos, sino aceptar su obsesiva inmediatez, llena de dolor e incertidumbre, pero atravesada por la experiencia de lo inefable y el misterio; recrear las historias en su contexto, pero también interpretarlas desde la subjetividad del protagonista; mantener cierta distancia crítica, pero comprometerme con la verdad; contar no sólo los recuerdos y viven- 
cias de Dan Kofler, sino mi propia indagación; narrar la historia individual de un judío singular, pero también su vinculación con la historia de nuestro país; hablar no sólo del pasado, sino del presente; interesar al lector por las aventuras y peripecias del personaje, pero sumergirlo al mismo tiempo en una reflexión profunda sobre el sentido de la vida y el misterio de la existencia.

La dificultad radicaba en encontrar un narrador verosímil, coherente y eficaz, capaz de hacer realidad todas estas intenciones comunicativas. Sólo la novela, como género abierto, podía en principio acoger un propósito tan ambicioso y aparentemente heterogéneo. Pero pronto comprendí que necesitaba rebasar sus límites, desbordar el género narrativo para poder escribir lo que necesitaba escribir. El resultado fue una integración de géneros (novela, cuento, ensayo, indagación histórica, poesía y escritura dramática) sobre la base de una estructura narrativa general asumida por tres voces: la del protagonista, la del escritor-autor, y la de un narrador impersonal que permite al lector distanciarse del relato de ambos narradores-personajes.

Es inevitable que haga referencia a la complejidad narrativa del Quijote. Cervantes es el primero en convertir la novela en un género capaz de integrar en ella otros géneros.

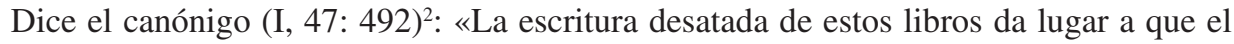
autor pueda mostrarse épico, lírico, trágico, cómico...». El propio Cervantes en el prólogo a la Segunda Parte afirma que sus novelas no podrían ser buenas «si no tuvieran de todo». También fue el primero en ser consciente de la importancia de la voz del narrador, claramente diferenciado del autor. El autor (Cervantes) acaba diluyéndose en el texto y confundiéndose con un narrador ficticio (Cide Hamete Benengeli) y con «otros autores» indefinidos. Cervantes no aparece, no está presente en el Quijote. Se borra conscientemente, deja la responsabilidad del texto a otro-s. No es sólo un truco para dotar de mayor verosimilitud y verdad a la historia, sino un medio para construir una especie de conciencia superior que le permita en todo momento jugar con la ambigüedad y la ironía, al mismo tiempo que priva de toda sustancia o entidad al autor, diluido entre una diversidad de voces narrativas.

Porque ¿quién habla en el Quijote? No encontramos en el texto una sola voz, sino una multiplicidad de voces. El narrador inicial, el primer sujeto de la enunciación, empieza usando la primera persona de singular («no quiero acordarme») pero enseguida pasa a la tercera («vivía un hidalgo»), para aclararnos luego que quien en realidad está hablando es otro (Cide Hamete Benengeli). La labor del primer narrador (el más cercano al autor), nos enteramos más adelante que sólo ha consistido en ser una especie de editor literario, pues ni siquiera se responsabiliza de la traducción del texto original «arábigo». En consecuencia, él no ha inventado la historia de don Quijote, sino que se ha limitado a transcribir (o reescribir) lo que otro-s historiador-es han escrito. Incluso llega a afirmar en el prólogo de la Primera Parte que él no es padre, sino el «padrastro» de esta obra. El narrador se vuelve difuso, escurridizo, para que la historia se haga más transparente. Sólo cuando el relato parece alejarse de lo verosímil, entonces interviene el narrador inicial para aclarar los hechos, quién y cómo se están contando. El efecto inmediato que este recurso literario produce en el lector es el de convertir la ficción en historia, en dotar

2 Miguel de Cervantes. Don Quijote de la Mancha. Madrid: Real Academia de la Lengua, 2005. 
de realidad lo que no es más que ficción. Los protagonistas (don Quijote y Sancho) se convierten ante el lector en personajes reales, históricos, no en entes de ficción. Muchos lectores de la época creyeron que efectivamente don Quijote y Sancho habían existido, que eran sus contemporáneos. El autor quedó borrado en -y por- su obra. Partiendo de la ficción literaria, Cervantes descubrió hasta qué punto la realidad está hecha de ficción, o cómo la ficción determina la realidad. Esta reversibilidad entre realidad y ficción se construye a partir de la disolución del autor en la voz del narrador. El proceso es el siguiente: el autor real se borra para que un narrador ficticio pueda construir una historia imaginaria que ocupe el lugar del mundo real. El mundo es realidad imaginaria y ficción real cuya única consistencia es la que le otorga el lenguaje.

Salvando las evidentes diferencias, la escritura de estas Memorias puede ser interpretada desde las mismas premisas. Para transmitir los hechos, la verdad de los hechos, necesité transformar la realidad en ficción literaria. Para contar una historia real, necesité convertir al protagonista (Dan Kofler) y al autor (Santiago Trancón) en personajes literarios. De la realidad he ido a la ficción para hacer más real (y problemática) la realidad.

El procedimiento consiste en que el sujeto de la enunciación (del discurso narrativo) convierte al sujeto empírico (extra-textual) en objeto del enunciado. El acto de narrar une a ambos, sujeto y objeto, producción y producto. El sujeto no está sólo en lo que dice, sino en el decir. En último término, en el lenguaje. El sujeto no tiene otra entidad que la que le otorga el lenguaje. La verdad está tanto en lo dicho como en el acto de decir, en lo narrado como en el acto de narrar. ¿Dónde queda el yo del autor?

La auténtica escritura es un acto de desprendimiento; y la literatura verdadera, un intento se superación y disolución de los límites del yo. El yo es un significante sin significado, dice Lacan. No tiene entidad, no es una sustancia permanente. El sujeto está constituido por la voz o el discurso del Otro. El acto de narrar pone de manifiesto la naturaleza imaginaria y simbólica (lingüística) del sujeto. No es el sujeto-autor una entidad creadora autónoma, una esencia de la que emana la obra literaria, sino una voz que transmite el discurso del Otro. El autor escribe «inscribiéndose» en el discurso de un sujeto que no es él mismo, sino un sujeto lingüístico, el sujeto de la enunciación. Todo esto produce el mismo efecto de extrañeza que la imagen del espejo: es ilusión, es evanescente, la identificación con ella no puede ser más que imaginaria. Lo real se escapa, no puede decirse. Lo dicho no es lo real, sino la imagen simbólica de lo real. La distancia entre lo real y el lenguaje es la misma que existe entre realidad y literatura.

La literatura da consistencia y permanencia a la vida. Esto lo sabe muy bien don Quijote quien desde su primera salida, vive sus aventuras con la conciencia de que van a ser contadas, escritas. Vive para que su vida se transforme en literatura.

Dichosa edad y siglo dichoso aquel adonde saldrán a la luz las famosas hazañas mías, dignas de entallarse en bronces, esculpirse en mármoles y pintarse en tablas, para memoria en lo futuro. ¡Oh tú, sabio encantador, quienquiera que seas, a quien ha de tocar el ser cronista de esta peregrina historia! (I, 2: 35).

Cervantes usa constantemente la expresión «la verdadera historia de don Quijote». ¿Es verdadera la historia de don Quijote? Sí, pero no en un sentido histórico, sino en un sentido literario. Cervantes sitúa las historias en un mundo real, con vagas referencias geográficas, que le sirven de «marco» para hacer más verosímil su relato. Pero esto lo 
hace sin ningún afán de «realismo» descriptivo, sino para dar mayor consistencia al mundo literario que inventa. Utiliza la ambigüedad, el encubrimiento y la imprecisión como recurso literario. La obra acaba así convirtiéndose en una realidad autónoma. La mayor prueba es que es capaz de tomar conciencia de sí misma. Cervantes acaba dando tanta autonomía a su obra, tanta libertad creativa al sujeto de la enunciación (el narrador) -y a los sucesivos narradores que irrumpen e interrumpen el relato general-, que es como si la propia obra tuviera conciencia de sí misma y se organizara desde dentro, no desde fuera. La obra llega así a influir sobre los propios personajes, que toman conciencia de sí mismos a través del relato que otros hacen de su vida.

Algo semejante ocurre en estas Memorias. Los 63 capítulos siguen el orden cronológico de la recepción del relato que el protagonista transmite al narrador testigo. Los hechos se cuentan en la medida en que son contados por el protagonista. Paralelamente, el narrador testigo se desdobla en dos voces: la suya y la de un narrador impersonal que se sitúa por encima de ambos (protagonista y testigo) para organizar el relato general. Se van transmitiendo así, de forma simultánea y paralela al relato biográfico del protagonista, los descubrimientos que ese narrador testigo hace de su propia historia familiar y del pasado judío de nuestro país. El relato va progresando en la medida en que se va escribiendo. Se unen el tiempo de la narración y el tiempo de la escritura. El acto de narrar no se separa del acto de escribir. En cada momento se cuenta sólo lo que el narrador testigo va conociendo. El texto así elaborado se concibe como un borrador provisional, o sea, como un texto inacabado que debe ser corregido y completado cuando el narrador conozca toda la historia que el protagonista le va a contar. Pero ese texto definitivo al final no va a poder ser escrito. ¿Por qué? Porque una vez escrito, el texto «no se puede modificar». La literatura no un juego provisional, sino, como la vida, un hecho definitivo, irreversible o inmodificable. Este recurso afianza la idea de que el libro acaba escribiéndose a sí mismo por encima del autor. Que el acto de narrar no es un mero pasatiempo, sino una experiencia en la que el sujeto no es más que eso, un significante encadenado, sujetado por la cadena del lenguaje.

El libro juega, en definitiva, a borrar las diferencias entre autor y narrador. La voz del autor real (Santiago Trancón, escritor) inicia y acaba el relato construyendo un marco que cumple la función de insertar el texto en una realidad extra-narrativa, pero a partir de aquí esa identificación explícita entre autor y narrador se rompe, se vuelve difusa. Por un lado, el narrador (que está del lado de la ficción) se hace progresivamente más real, pasando de ser nombrado con un «él» a identificarse con el nombre del autor; pero, por otro, el autor (que está en el mundo real) desaparece para asumir la voz del narrador (o sea, una voz ficticia al servicio del relato). Otro tanto sucede con el protagonista Dan Kofler, pues es a la vez persona real y personaje literario. La persona real se vuelve personaje al convertirse en sujeto de la enunciación de su propia historia (autobiográfica), pero también en objeto del enunciado, tanto de su relato como del relato que de él hace el otro personaje, el narrador testigo. Este narrador testigo, a su vez, se convierte en personaje, sujeto de la enunciación de sus propias referencias biográficas y familiares y objeto del enunciado del narrador impersonal. El narrador impersonal amplía de este modo las posibilidades narrativas, introduciendo al lector en un mundo dialógico (Bajtin), polifónico y diverso. 
Si recurrimos a Gérard Genette podremos hablar de que una misma instancia narrativa se multiplica y diversifica para hacer posible todas las intenciones del autor. Encontramos en esta obra un narrador homodiegético, autodiegético, heterodiegético, intra y extradiegético, con varias de sus combinaciones posibles. Los polos extremos se situarían entre un narrador-protagonista autodiegético -que usa el diálogo, el monólogo simple y el monólogo interior- y un narrador heterodiegético omnisciente (aunque limitado), que controla el orden general del relato. El horizonte hacia el que este narrador múltiple se dirige es el de la verdad literaria, que no es otra cosa que un equilibrio entre realidad y ficción (verosimilitud). Ya lo expresó muy bien Cervantes en el Quijote: «Bien -dijo el cura- me parece esta novela, pero no me puedo persuadir que esto sea verdad; y si es fingido, fingió mal el autor» (I, 35: 374).

El narrador ha de ser capaz de persuadir al lector de que lo que cuenta es verdad, y si es ficción, ha de fingir bien el autor para que tenga la apariencia de verdad; o sea, que siempre ha de ser verosímil el relato. Para transmitir una verdad, la literatura ha de crear un mundo verosímil. Lo difícil consiste muchas veces, no en contar una verdad, sino en hacerla literariamente verosímil. Para evitar que muchas de las experiencias insólitas del protagonista de estas Memorias, Dan Kofler, no fueran tomadas por inverosímiles, tuve que darles una apariencia literaria. Tanto es así que muchos lectores tardan en darse cuenta de que no son inventadas, que responden a vivencias y hechos reales. Para que la realidad se vuelva más real debe distanciarse y producir, paradójicamente, cierto efecto de extrañeza, que es lo que la literatura consigue. Al romper el automatismo del lenguaje, la literatura revela el poder de la conciencia, que hace más real y verdadero el mundo inasible que crea. La conciencia de sí mismo, al superar los límites de la identificación imaginaria del sujeto con el yo, se convierte en la verdadera fuente del acto de escribir, en una instancia autónoma que sostiene y dirige el acto de narrar por encima del autor.

El yo es efecto del lenguaje, un significante inscrito en una cadena de significantes. Este vacío de significado (la falta) nos lleva a la literatura, ese mundo que cobra la apariencia del ser algo permanente que se ofrece a los otros como realidad autónoma y autosuficiente. El autor se identifica imaginariamente con el narrador porque quisiera ser algo más que un significante, una voz pronunciada por otros. Escribe para inscribirse en la obra, pero su ser queda afuera, irremediablemente. Por eso toda obra es para su autor una creación extraña que le obliga a interrogarse sobre el misterio de su propia conciencia, de la que el yo no es más que una ilusión de eternidad.

\section{REFERENCIAS BIBLIOGRÁFICAS}

Albaladejo, T. (1986). Teoría de los mundos posibles y macroestructura narrativa. Alicante: Universidad de Alicante.

Bajtin, M. (1982). Estética de la creación verbal. México: Siglo XXI.

- (1989). Teoría y estética de la novela. Madrid: Taurus.

Cervantes, M. (2004). Don Quijote de la Mancha. Madrid: Real Academia de la Lengua Española.

Ducrot, O. (1984). El decir y lo dicho. Polifonía de la enunciación. Barcelona: Paidós.

García Berrio, A. (1994). Teoría de la literatura (la construcción del significado poético). Madrid: Cátedra. 
LaCAN, J. (1971) «El estadio del espejo como formador de la función del Yo», en Escritos 1. México: Siglo XxI.

- (1983). El yo en la teoría de Freud y en la técnica psicoanalítica, de El seminario Libro 2 (1954-55). Barcelona: Paidós.

- (1984). «Subversión del sujeto y dialéctica del deseo en el inconsciente freudiano», en Escritos 2. México: Siglo XXI.

Garrido Domínguez, A. (1993). El texto narrativo. Madrid: Síntesis.

Genette, G. (1998). Nuevo discurso del relato. Madrid: Cátedra.

IsER, W. (1997). «La ficcionalización: dimensión antropológica de las ficciones literarias», en Teorías de la ficción literaria, ed. De M. A. Garrido Domínguez. Madrid: Arco/Libros.

Morales, J. R. (2006). Cervantinas y otras páginas. Valladolid: Fundación Jorge Guillén.

Todorov, T. (1988) «El origen de los géneros», en Teoría de los géneros literarios, 31-48. M. A. Garrido Gallardo ed. Madrid: Arco/Libros.

Trancón, S. (2006).Teoría del Teatro. Madrid: Fundamentos.

- (2011). Memorias de un judío sefardí. La verdadera historia de Dan Kofler. Madrid: Infova Ediciones.

Villanueva, D. (1992). Teoría del realismo literario. Madrid: Instituto de España/ Espasa Calpe. 